\title{
An investigation of a new 2D CDM model in predicting failure in HFQing of an automotive panel
}

\author{
Mohamed Mohamed ${ }^{1,2, a}$, Nan Li ${ }^{1}$, Liliang Wang ${ }^{1}$, Omer El Fakir ${ }^{1}$, Jianguo Lin ${ }^{1}$, Trevor Dean ${ }^{1}$, \\ and John Dear ${ }^{1}$ \\ ${ }^{1}$ Department of Mechanical Engineering, Imperial College London, London SW7 2AZ, UK \\ ${ }^{2}$ Mechanical Engineering Department, Faculty of Engineering, Helwan University, Egypt
}

\begin{abstract}
In this paper a comparative analysis of failure prediction when using the solution heat treatment cold die forming and quenching process, known as $\mathrm{HFQ}^{\mathrm{TM}}$, for forming an aluminium alloy AA6082 automotive panel part (bulkhead panel), is presented. An experimental programme has been designed and a series of tests have been carried out to investigate the effect of process parameters on the success of forming the complex-shaped automotive panel component using the high strength aluminium alloy. A set of unified viscoplastic plane-stress continuum damage mechanics (2D-CDM) constitutive equations was calibrated for AA6082 over a temperature range of $450{ }^{\circ} \mathrm{C}-525^{\circ} \mathrm{C}$ and strain rates of $0.1,1.0$ and $10 \mathrm{~s}^{-1}$, and then was integrated into the commercial finite element code, LS-DYNA, via a user-defined material subroutine, UMAT, for the forming process simulation. The results show that the CDM model can be used to provide accurate formability and failure predictions.
\end{abstract}

\section{Introduction}

The use of the lightweight materials, such as aluminium alloys, is increasing significantly, particularly for automotive applications. Although aluminium alloys have many advantages compared with steel, their formability is lower at room temperature and using them for manufacturing complex shapes, particularly from sheet, is difficult and creates additional design challenges [1]. To overcome the formability problem, hot stamping processes have been developed. For example, in the process of hot stamping and cold die quenching $\left(\mathrm{HFQ}^{\mathrm{TM}}\right)$, an aluminium alloy is heated to its solution heat treatment temperature (or close to it) prior to forming stage. It is then press formed in cold dies thereby being quenched and retaining a solid solution [2].

\section{Experimental programme}

Forming trials of the bulk head were carried out on a 100-ton high speed hydraulic press with a custom tool and die set as shown in Fig. 1(a and b). These trials were carried out based on the optimization of process parameters (temperature, time, friction (lubricant) and blank holding force) to achieve successful deformed parts. The deformation trials were carried out at room temperature and at HFQ conditions.

\footnotetext{
${ }^{\text {a }}$ Corresponding author: mmohamed@imperial.ac.uk
}

This is an Open Access article distributed under the terms of the Creative Commons Attribution License 4.0, which permits unrestricted use, distribution, and reproduction in any medium, provided the original work is properly cited. 


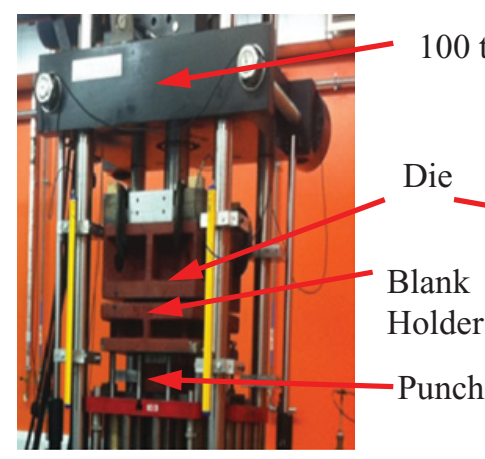

(a) Test set-up (b) Tool Set

Figure 1. Test facilities and set-up.

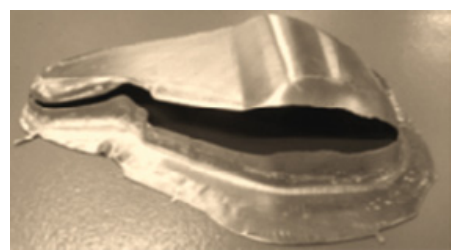

(a) Cold formed part

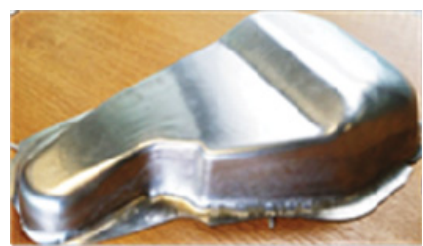

(b) HFQ formed part

Figure 2. Formed parts using, (a) cold and (b) HFQ-aluminium forming technologies.

Figures $2 \mathrm{a}$ and $\mathrm{b}$ show the experimental results of parts formed at room temperature and under a HFQ condition, respectively. It is apparent that the cold formed part fractured and the HFQ formed part did not fail.

\section{Development of multi-axial viscoplastic damage constitutive equations}

A novel plane-stress continuum damage mechanics (CDM) model for the prediction of failure under hot stamping conditions has been investigated. The model was calibrated from tensile experimental data of AA6082 at a temperature range of $450{ }^{\circ} \mathrm{C}-525^{\circ} \mathrm{C}$ and strain rates of $0.1 \mathrm{~s}^{-1}, 1.0 \mathrm{~s}^{-1}$ and $10 \mathrm{~s}^{-1}$ (Lin et al. 2014). A set of multi-axial viscoplastic constitutive equations, incorporating multiaxial damage evolution, is formulated as:

$$
\begin{gathered}
\dot{\varepsilon}_{e}^{p}=\left(\frac{\sigma_{e} /(1-\omega)-R-k}{K}\right)^{n} \\
\dot{\varepsilon}_{i j}^{p}=\frac{3}{2} \frac{S_{i j}}{\sigma_{e}} \dot{\varepsilon}_{e}^{p} \\
\dot{R}=0.5 B \bar{\rho}^{-0.5} \dot{\bar{\rho}} \\
\dot{\bar{\rho}}=A(1-\bar{\rho}) \dot{\varepsilon}_{e}^{p}-C \bar{\rho}^{n_{2}}
\end{gathered}
$$


Table 1. Material constants of CDM model calibrated for AA6082 at elevated temperatures.

\begin{tabular}{|c|c|c|c|c|c|c|c|c|c|}
\hline$K_{0}(\mathrm{MPa})$ & 0.702 & $A_{0}(-)$ & 8.139 & $Q_{\eta_{1}}$ & 12030 & $\eta_{1_{0}}(-)$ & 0.00899 & $\alpha_{1}$ & 0.4 \\
\hline$k_{0}(\mathrm{MPa})$ & 2.518 & $n_{0}(-)$ & 0.6451 & $Q_{\eta_{2}}$ & 953 & $Q_{C}$ & 128828 & $\alpha_{2}$ & -0.072 \\
\hline$B_{0}(\mathrm{MPa})$ & 0.7222 & $Q_{K}$ & 22940 & $Q_{A}$ & 6411 & $n_{2}$ & 1.8 & $\alpha_{3}$ & 0.05 \\
\hline$C_{0}\left(\mathrm{~s}^{-1}\right)$ & 102567 & $Q_{k}$ & 8857 & $Q_{n}$ & 14325 & $\eta_{2_{0}}(-)$ & 0.8362 & $\Delta$ & 0.8 \\
\hline$E_{0}(\mathrm{MPa})$ & 8.855 & $Q_{B}$ & 19489 & $\eta_{3}$ & 17 & $Q_{E}$ & 45766 & $\varphi$ & 4 \\
\hline
\end{tabular}

$$
\begin{gathered}
\sigma_{i j}=(1-\omega) D_{i j k l}\left(\varepsilon_{i j}-\varepsilon_{i j}^{p}\right) \\
\dot{\omega}=\frac{\Delta}{\left(\alpha_{1}+\alpha_{2}+\alpha_{3}\right)^{\varphi}}\left\langle\frac{\alpha_{1} \sigma_{I}+3 \alpha_{2} \sigma_{H}+\alpha_{3} \sigma_{e}}{\sigma_{e}}\right\rangle^{\varphi} \cdot \frac{\eta_{1}}{(1-\omega)^{\eta_{3}}}\left(\dot{\varepsilon}_{e}^{p}\right)^{\eta_{2}} .
\end{gathered}
$$

Where $D_{i j k l}$ is the elastic matrix of the material. The multiaxial damage Eq. (6) is extended from the uniaxial form with consideration of the multiaxial stress-state effects. $\alpha_{1}, \alpha_{2}$ and $\alpha_{3}$ are used to calibrate the effect of maximum principal stress, hydrostatic stress and effective stress on damage evolution respectively. Symbol $\varphi$ represents a parameter which controls the effect of multi-axial stress values and their combination on damage evolution, thus determines formability. Symbol $\Delta$ is for a correction factor representing tensile data obtained from uniaxial tensile tests, or as suggested by Marciniak, et al. (1973) and Nakazima, et al. (1968), formability tests, for which different strain measurement methods are normally used (Lin et al. 2014 and Mohamed et al. 2014). The material constants of CDM model for AA6082 at elevated temperatures are shown in Table 1 (Mohamed et al. 2014). The constants $K, k$, $E, B, C, A, n, \eta_{1}, \eta_{2}$ are temperature dependent parameters and formulated by Arrhenius equations as shown Mohamed et al. (2012):

$$
\begin{array}{lll}
K=K_{0} \exp \left(Q_{K} / R_{g} T\right) & B=B_{0} \exp \left(Q_{B} / R_{g} T\right) & E=E_{0} \exp \left(Q_{E} / R_{g} T\right) \\
C=C_{0} \exp \left(-Q_{C} / R_{g} T\right) & \eta_{1}=\eta_{1_{0}} \exp \left(Q_{\eta_{1}} / R_{g} T\right) & \eta_{2}=\eta_{2_{0}} \exp \left(-Q_{\eta_{2}} / R_{g} T\right) \\
A=A_{0} \exp \left(-Q_{A} / R_{g} T\right) & n=n_{0} \exp \left(Q_{n} / R_{g} T\right) . &
\end{array}
$$

\section{Process simulations}

\subsection{FE model}

An FE model has been created and validated using experimental results. Studies have been carried out to validate the novel CDM model. FE simulation of Bulkhead part forming at elevated temperatures was conducted for AA6082 aluminium alloy using an FE code LSDYNA and the coupled temperaturedisplacement deformation mode. The sheet was meshed using quadratic elements, with five elements through the thickness to ensure through-thickness bending strain could be captured, although the sheet deformation in the simulations almost exclusively stretches. The CDM constitutive equations for AA6082 was implemented via the user defined subroutine, UMAT. A schematic diagram of the FE model with boundary conditions is shown in Fig. 3. The effect of heat transfer coefficient, HTC, was investigated by Foster, et al. 2008 [22], and the value of heat transfer coefficient was found to be, $1.4\left(\mathrm{mw} / \mathrm{mm}^{2} . \mathrm{C}\right)$

\subsection{Experimental validation}

The process simulation was used to obtain a comparison of the ability to predict failure using either the conventional FLD method, or the CDM model incorporated with FE software, relative to experimental results. The CDM model was used also to predict formability and thinning at elevated temperature. 


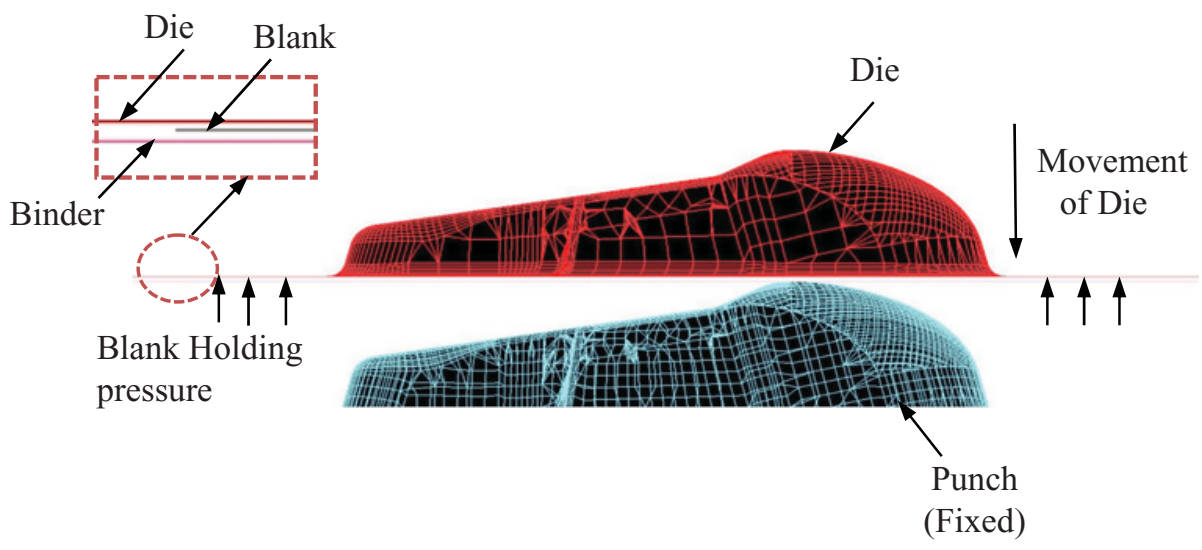

Figure 3. FE process model built in LSDYNA.

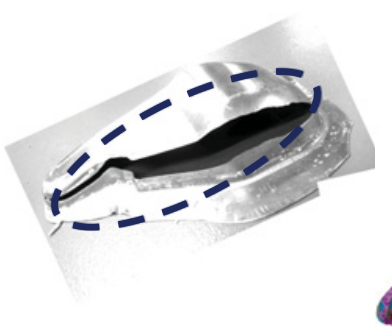

(a)

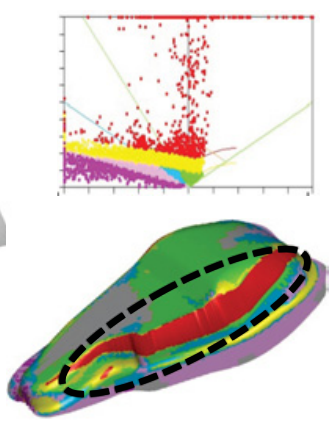

(b)

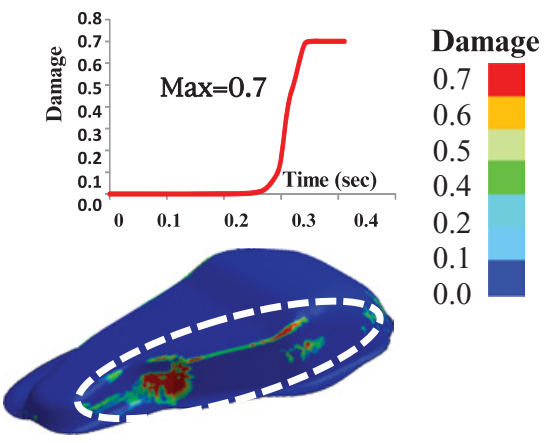

(c)

Figure 4. Comparison of failure regions in cold formed bulkhead panels: a) experimental, b) FE computed by standard FLD failure criterion model and c) FE simulated by using CDM failure criterion model.

\subsection{Formability and failure feature at room temperature}

Figures 4(a), (b) and (c) show failure locations in the bulkhead panels, formed at $20^{\circ} \mathrm{C}$, from practical experiment and simulation using both the standard FLD (model) and numerical CDM. It can be observed that failure predicted by both FLD and CDM models occurred at the same location and in consistent with the experimental result. Qualitatively, the simulations are in a good agreement with the experiments, which suggests that the continuum damage equations set is correctly formulated and implemented. This result confirms a good agreement between the FLD and CDM models at $20{ }^{\circ} \mathrm{C}$, at only which temperature the FLD can be used successfully.

\subsection{Formability and failure prediction at HFQ conditions}

Figures 5(a), (b) and (c) (I and II) illustrate another validation of the CDM model. It represents the experimental and FE simulation computed results of the formability of the bulkhead panel deformed at $470{ }^{\circ} \mathrm{C}$ and with forming speed of $400 \mathrm{~mm} / \mathrm{sec}$. At a high friction condition $(\mu=0.25)$, the part was deformed unsuccessfully and the failure took place in the experiment, see Fig. 5a-I. The FE model shows also the failure of the sample (Fig. 5b-I) at this condition and it is nearly close to the sample 
(I)
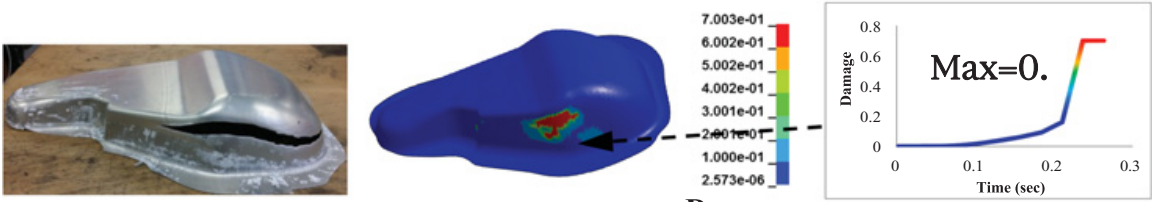

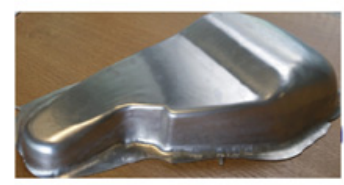

(a)

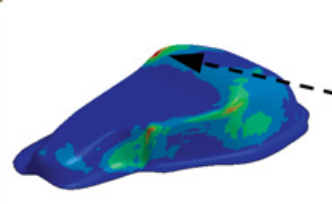

(b)
Damage

2.425e-02

2.078 - 02

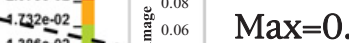

$1.039 \mathrm{e}-02$

$6.930 \mathrm{e}-03$

$3.466 \mathrm{e}-03$

$2835 \mathrm{e}-06$

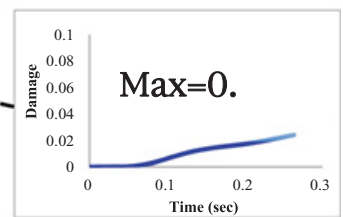

(c)

Figure 5. Comparison of experimental and FE CDM model predicted results at HFQ conditions with two friction coefficient values: (I) $\mu=0.25$ and (II) $\mu=0.1$, where (a) pictures of HFQ formed parts (b) damage distribution on the FE simulated parts, (c) damage evolution curves at critical location of the part.

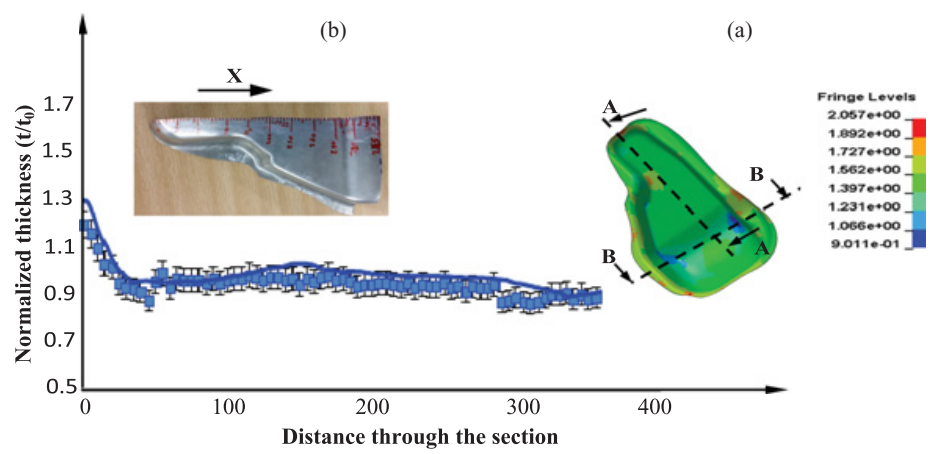

Figure 6. Comparison of experimental (symbols) and FE simulation (solid curve) results of normalized thickness distribution along section plane A-A, (a) A FE simulated bulkhead showing cutting sections and thickness distribution which is converted to normalized thickness distribution (b) a part of formed bulkhead cut long A-A section.

failure location occurred in experiment. The damage value reaching 0.7 indicates the failure occurrence as shown in damage curve in Fig. 7c-I. By adjusting the friction coefficient in a proper value $(\mu=0.1)$ by applying a suitable type of lubricant (wisera), the part was successfully formed (see Fig. 5a-II). Again, the same forming result was achieved via FE model as shown in Fig. 5b-II. The damage value (in Fig. 5c-II) is very small and close to zero $(\omega \ll 0.7)$, which confirms that the part was successfully deformed. There is a good agreement between the CDM model predicted and the experimental results part.

\subsection{Localized thinning at HFQ conditions}

Figure 6 shows the normalized thickness $\left(t / t_{0}\right)$, where $t_{0}$ is the initial sheet thickness, $t$ is the measured thickness on the section plane A-A of a formed part. Solid symbols and the solid curve present experimental results and FE simulated results, respectively. A good agreement can be observed. The results in the Figure quantitatively show that the minimum value of $t / t_{0}$ is at the end of the section where the deepest draw occurred. There is thickening at the front of the part due to severe wrinkling, indicated by both experimental and FE simulation results. 


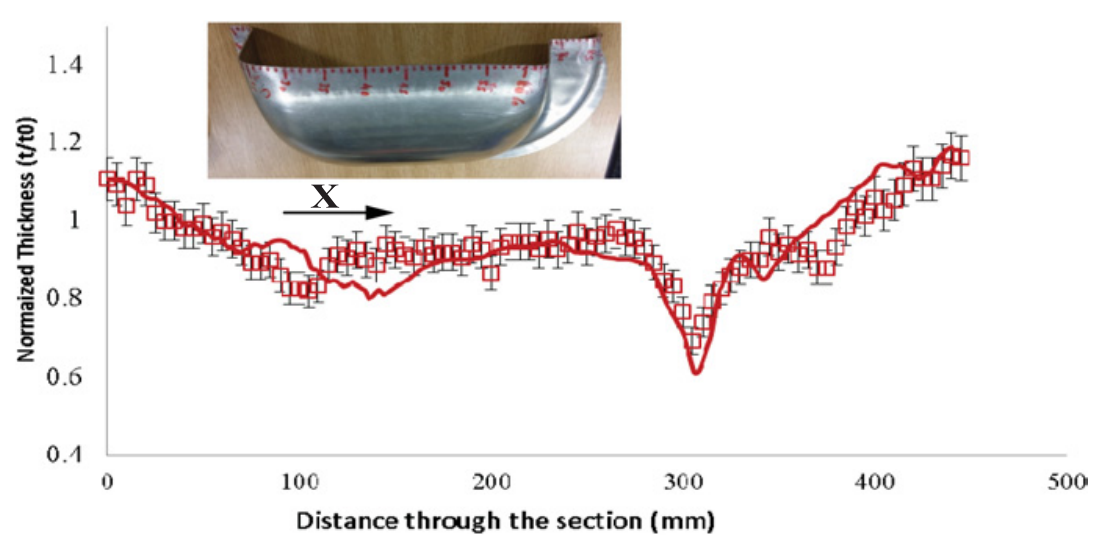

Figure 7. Comparison of normalised thickness distribution measured from FE simulation (solid curve) and experiments (symbols) for section B-B.

To explore this further, the normalised thickness $\left(\mathrm{t} / \mathrm{t}_{0}\right)$ distribution along the cross section B-B of the formed bulkhead part was measured from experiment and FE simulation results. As shown in Fig. 10, significant necking can be observed at the top corner of the part from both results. The agreement between the experimental and simulation measurements is fairly good.

Hence, Figs. 4 to 7 confirm that the constitutive CDM equations and FE model implementation is capable of predicting deformation and failure features for HFQ processes for AA6082 bulkhead panel parts.

\section{Conclusions}

This paper presents comparative analysis of failure prediction of an aluminium alloy AA6082 real automotive panel part deformed under HFQ conditions. The part has been formed successfully through experimental trials. In order to predict the failure of the part and check the viability of the prototype tool design, a novel plane-stress continuum damage mechanics (CDM) model for the prediction of failure under hot stamping conditions has been investigated. The model was calibrated from tensile experimental data of AA6082 at a temperature range of $450{ }^{\circ} \mathrm{C}-525^{\circ} \mathrm{C}$ and strain rates of $0.1 \mathrm{~s}^{-1}, 1.0 \mathrm{~s}^{-1}$ and $10 \mathrm{~s}^{-1}$ and the FLD data at $20^{\circ} \mathrm{C}$ for AA6082. The calibrated CDM model has been implemented into the commercial finite element code LS-DYNA via a user-defined material subroutine, UMAT. A FE model has been created and validated from experimental results. The results indicate that the CDM model allows accurate predictions of formability and failure.

\section{References}

[1] M. Mohamed, A. Foster, J. Lin, Steel Research International, 79 (11), VII, pp. 160-167 (2008)

[2] M. Mohamed, A. Foster, Lin, J. D. Balint, T. A. Dean, Steel Res Int., 81, 9 (2008)

[3] Keeler S.P., Sheet Met. Ind., 42 (1965)

[4] Goodwin G.M., Metall. Italiana, 60, pp. 764-74 (1968)

[5] Lin, J., Mohamed, M., Balint, D., Dean, T.A., Int. J of Damage Mech., 23(5) (2014)

[6] M. Mohamed, A. Foster, J. Lin, D. Balint, T.A. Dean, Int J Mach Tool Manu 53 (2012) 